\title{
Leakage of fluid around endotracheal tube cuffs: a cadaver study
}

\author{
Falk Birkenfeld ${ }^{1}$, Ralph Lucius ${ }^{1}$, and Kristian Ewald ${ }^{2}$ \\ ${ }^{1}$ Institute of Anatomy, Christian-Albrechts University, Kiel, ${ }^{2}$ Department of Research and Development, Schülke \& Mayr GmbH, \\ Norderstedt, Germany
}

Background: The aim of the study was to evaluate the leakage of liquid past the cuffs of tracheal tubes in fresh frozen human heads.

Methods: Six truncated fresh frozen heads were used and intubated with $8.0 \mathrm{~mm}$ endotracheal tubes. The intracuff pressures tested were 30 and $100 \mathrm{cmH}_{2} \mathrm{O}$. Subsequently, $20 \mathrm{ml}$ of each of two oral antiseptic rinses $(0.2 \%$ chlorhexidine and octenidine [octenidol ${ }^{\circledR}$, Schülke \& Mayr GmbH, Norderstedt, Germany]) was applied for thirty seconds in the mouth. During the trial, leakage of the cuffs was examined.

Results: The sealing between the tracheal cuff and tracheal wall was leakage-proof for all tested intracuff pressures and all tested antiseptic rinses. However, approximately $5.6 \mathrm{ml}$ and $1.8 \mathrm{ml}$ leaked into the esophagus and remained as a cuffpuddle, respectively.

Conclusions: The sealing between an endotracheal tube cuff with an intracuff pressure of $30 \mathrm{cmH}_{2} \mathrm{O}$ and the tracheal wall is leakage-proof during oral care with antiseptic rinsing. An increase of intracuff pressure to $100 \mathrm{cmH}_{2} \mathrm{O}$ does not appear to be required. (Korean J Anesthesiol 2013; 65: 438-441)

Key Words: Aspiration, Oral hygiene, Tracheal cuff.

\section{Introduction}

Ventilator-associated pneumonia occurs in approximately $25 \%$ of intensive care patients [1]. Oral care with antiseptic rinsing is the recommended strategy [2]. Chlorhexidine is often known as the gold standard, based on many studies [3]. However, this compound exhibits toxic side effects in the lungs $[3,4]$.
Octenidine dihydrochloride (octenidine) is also used as an antiseptic oral rinse and has better results documented with respect to gingivitis prophylaxis and plaque inhibition $[5,6]$.

An endotracheal cuff serves as protection against aspiration [7]; however, cuff leakages have been described that support downward flows of pathogens into the lungs [8,9]. An intracuff pressure of $30 \mathrm{cmH}_{2} \mathrm{O}$ should be used by intensive care patients

Received: May 28, 2013. Revised: 1st, June 21, 2013; 2nd, June 25, 2013; 3rd, June 28, 2013; 4th, July 2, 2013; 5th, July 4, 2013 ; 6th, July 5, 2013. Accepted: July 9, 2013.

Corresponding author: Falk Birkenfeld, M.D., Institute of Anatomy, Christian-Albrechts University, Otto-Hahn-Platz 8, Kiel 24118, Germany. Tel: 49-431-880-3796, Fax: 49-431-880-1557, E-mail: f.birkenfeld@anat.uni-kiel.de

(c) This is an open-access article distributed under the terms of the Creative Commons Attribution Non-Commercial License (http:// creativecommons.org/licenses/by-nc/3.0/), which permits unrestricted non-commercial use, distribution, and reproduction in any medium, provided the original work is properly cited. 
to prevent intratracheal ulceration and necrosis [10,11]. However, oral care intracuff pressures of $100 \mathrm{cmH}_{2} \mathrm{O}$ can be used to prevent downward flows due to reported cuff folds $[7,8]$.

The objective of this study was to evaluate the leakage resistance of endotracheal tubes with different intracuff pressures (30 and $100 \mathrm{cmH}_{2} \mathrm{O}$ ) in body donors undergoing oral care with $0.2 \%$ chlorhexidine or octenidine.

\section{Materials and Methods}

Six fresh frozen truncated heads (two males and four females; $78.3 \pm 8.6$ years) from individuals who had donated their bodies for medical research were used. The donors were stored frozen within $24 \pm 6 \mathrm{~h}$ after their passing. Eighteen hours before the study, each head was defrosted at room temperature $\left(20-22^{\circ} \mathrm{C}\right)$.

A Magill endotracheal tube (Endosid ${ }^{\circledR}$ polyvinyl chloride tube, $8.0 \mathrm{~mm}$, cylindrical cuff [about $24 \times 30 \mathrm{~mm}$ ], REF 841075 , ASID Bonz GmbH, Herrenberg, Germany) was gently inserted into the trachea $(20 \mathrm{~cm}$ measured from the lips; for each donor a new endotracheal tube was used), and using a calibrated highvolume, low-pressure manometer (VBM Cuff Pressure Gauge, VBM GmbH, Sulz, Germany), the cuff was inflated at a rate of $1 \mathrm{ml} / \mathrm{sec}$ (cuff volume: about $10 \mathrm{ml}$, inflation time: about $10 \mathrm{~s}$ ) to approximate the intended intracuff pressure $\left(30\right.$ or $100 \mathrm{cmH}_{2} \mathrm{O}$ ) and was allowed to stabilise for $10-15 \mathrm{~s}$ at the desired pressure.

The inflation volume was recorded, and $20 \mathrm{ml}$ of octenidine solution (Octenidol ${ }^{\circledR}$, Schülke\&Mayr GmbH, Norderstedt, Germany; viscosity: $1 \mathrm{mPa} \cdot \mathrm{s}$ [comparable to $\mathrm{H}_{2} \mathrm{O}$ ]) or $0.2 \%$ chlorhexidine solution (Meridol ${ }^{\circledR}$ med, GABA GmbH, Lörrach,

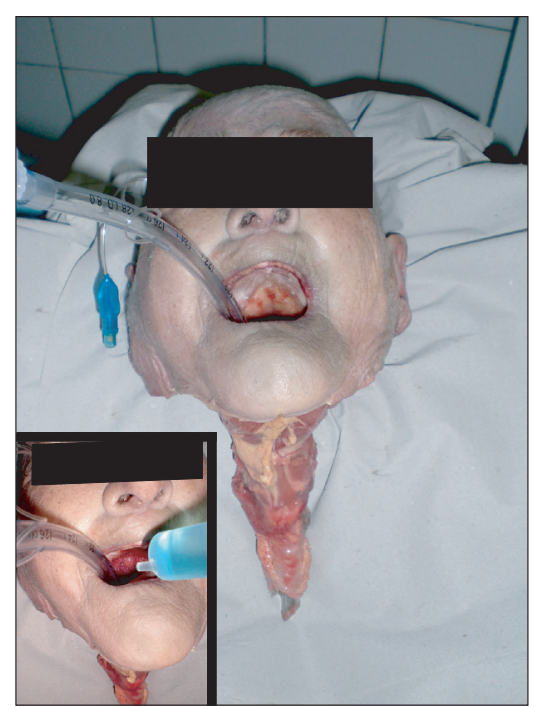

Fig. 1. Head-and-neck dissection. A body donor intubated with an 8.0 $\mathrm{mm}$ endotracheal tube. The esophagus, larynx and a part of the trachea were retained after abscission of the head. Inset: The application of the oral rinse with a $20 \mathrm{ml}$ syringe.
Germany; viscosity: $1 \mathrm{mPa} \cdot \mathrm{s}$ [comparable to $\mathrm{H}_{2} \mathrm{O}$ ]) was applied in the mouth (Fig. 1). The volume of the solvent running beyond the cuff in $30 \mathrm{~s}$ was measured by collection in a plastic cup. Next, the incorporated solvent was evacuated using a vacuum pump (Eydam Satorious Stedim Membran-Vakuumpumpe, REF 9604072, Erich Eydam KG, Kiel, Schleswig-Holstein, Germany), with control of the remaining agent checked by visual inspection. During the trial, the esophagus was compressed, and subsequently, any oral rinse that had run beyond the esophagus was collected.

After deflating the cuff, the oral rinse that had run beyond the cuff was collected.

Moreover, after the first test procedure, the larynxes $(n=6)$ were separated from the heads, and tubes were gently inserted into the tracheas (Fig. 2). Next, $2 \mathrm{ml}$ of the oral rinse was applied

Table 1. Test Procedures

\begin{tabular}{lcc}
\hline & No. 1 & No. 2 \\
\hline Dissection & Head-and-neck & Larynx \\
Angle of larynx $\left({ }^{\circ}\right)$ & 45 & 90 \\
Oral rinse & $0.2 \%$ chlorhexidine and octenidine \\
Amount of application $(\mathrm{ml})$ & 20 & 2 \\
Intracuff pressures $\left(\mathrm{cmH}_{2} \mathrm{O}\right)$ & \multicolumn{3}{c}{30 and 100} \\
Trial duration $(\mathrm{min})$ & 0.5 & 5 \\
\hline
\end{tabular}

From top to bottom the following steps were performed. In test No. 1 and No. 2, chlorhexidine and octendine, and 30 and $100 \mathrm{cmH}_{2} \mathrm{O}$ were used. Differences between the two tests were found in trial duration, amount of application and the angle of the larynx given by the anatomical dissections.

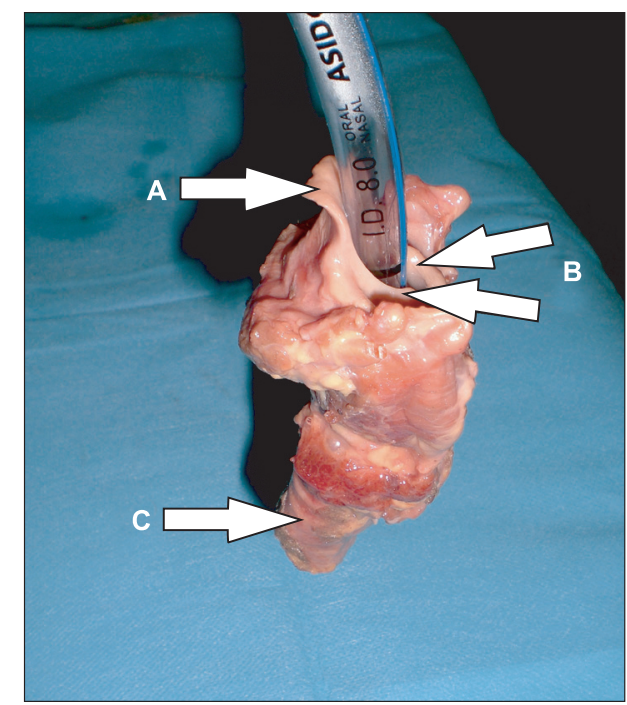

Fig. 2. Laryngeal dissection. The larynx was intubated with an endotracheal tube $(8.0 \mathrm{~mm})$, and $2 \mathrm{ml}$ oral rinse was applied from above. The $\mathrm{A}$ indicates the epiglottis, the $\mathrm{B}$ indicates the vote lips, and the $\mathrm{C}$ indicates the trachea. 
above each cuff. The volume of oral rinse running beyond the cuff in $5 \mathrm{~min}$ was measured by collection in a plastic cup. The sequence of the heads and the sequence of the oral rinse were randomized. The laboratory setting is summarised in Table 1.

\section{Statistical analysis}

Statistical analysis was performed with a t-test for the parametrically distributed (Kolmogorov-Smirnov test; $\mathrm{P}=0.94$ ) data using the WinStat Excel Add-In (Version 2007.1, R. Fitch Software, Bad Krozingen, Germany) (significance level: $\mathrm{P}<0.05$ ).

Between all tested groups ( 30 and $100 \mathrm{cmH}_{2} \mathrm{O}$, chlorhexidine and octenidine), there were no significant differences in the volume of leaked oral rinses into the esophagus $(\mathrm{P}=0.82)$ and trachea $(\mathrm{P}=0.25)$, respectively.

\section{Results}

\section{Head-and-neck dissection}

There was no leakage observed at any of the tested cuffpressures ( 30 and $100 \mathrm{cmH}_{2} \mathrm{O}$ ) of any tested antiseptic oral rinse ( $0.2 \%$ chlorhexidine and octenidine).

However, after the evacuation of the antiseptic oral rinse, there was a discrepancy of $176 \mathrm{ml}$ (133 $\mathrm{ml}$ rinsed into the esophagus and $43 \mathrm{ml}$ beneath the cuff) between the applied volume $(480 \mathrm{ml})$ and the evacuated volume $(304 \mathrm{ml})$.

Approximately $133 \mathrm{ml}$ (30\% of the applied antiseptic rinse [average $5.56 \mathrm{ml}$ for each trial $(5.56 \mathrm{ml} \times 24$ trials $=133 \mathrm{ml}$ ] $)$ leaked into the esophagus.

The remaining $43 \mathrm{ml}$ (10\% of the applied antiseptic rinse [average $1.8 \mathrm{ml}$ for each trial $(1.8 \mathrm{ml} \times 24$ trials = $43 \mathrm{ml})$ ] $)$ was evaluated as a cuff-puddle that was revealed beneath the cuff after deflating.

The oral rinses did not run beyond the cuffs either during the application of the rinse or during the residence time of $30 \mathrm{~s}$. The volume of agent remaining after evacuation was $5.5 \mathrm{ml}$ (minmax: 1.6-9.1 ml).

\section{Larynx dissection}

During the application time of $5 \mathrm{~min}$, there was no leakage observed at any of the tested cuff pressures $\left(30\right.$ and $\left.100 \mathrm{cmH}_{2} \mathrm{O}\right)$ for any of the tested antiseptic rinses $(0.2 \%$ chlorhexidine and octenidine). The sealing between the endotracheal tube cuff and the tracheal wall was leakage-proof.

No agent ran beyond the cuffs after $5 \mathrm{~min}$ at cuff pressures of 30 and $100 \mathrm{cmH}_{2} \mathrm{O}$. The complete volume of $2 \mathrm{ml}$ remained above the cuff.

\section{Discussion}

This study is the first to report results concerning the possible leakage of endotracheal cuffs during the application of chemotherapeutic agents with retentivity effects of about 24 hours in human heads. Various data have been published regarding cuff folds, which permit the aspiration of regurgitated gastric fluid or oral secretions $[8,9]$.

Cuffed endotracheal tubes are important for airway management, and the maintenance of cuff pressure should not be neglected. A cuff pressure of approximately $30 \mathrm{cmH}_{2} \mathrm{O}$ is adequate for leakage protection in airway management [10,11]. Our results support this pressure of $30 \mathrm{cmH}_{2} \mathrm{O}$ during oral care with oral rinsing. Pressure over $30 \mathrm{cmH}_{2} \mathrm{O}$ compresses the mucosal capillaries and impairs blood flow, with total occlusion occurring at $50 \mathrm{cmH}_{2} \mathrm{O}[12,13]$; thus, 15 minutes is the maximum duration for the safe use of this pressure [10]. In our study we used 30 and $100 \mathrm{cmH}_{2} \mathrm{O}$ for the intracuff pressure. The $30 \mathrm{cmH}_{2} \mathrm{O}$ represented the routine cuff pressure used in our intensive care unit, and $100 \mathrm{cmH}_{2} \mathrm{O}$ is used for the duration of the oral care with the oral rinse (about $30 \mathrm{~s}$ ). The five minutes of application in the laryngeal dissection was performed to test the maximum load.

Chlorhexidine is often referred to as the gold standard, based on many studies [3]. However, this chemical causes toxic side effects in the lungs $[3,4]$. Octenidine is also used as antiseptic oral rinse and has better results documented with respect to gingivitis prophylaxis and plaque inhibition $[5,6]$. It appears that octenidine will be the next gold standard due to its lack of side effects. Our results show that there is no influence on cuff leakage based on either the chemotherapeutic agent used $(0.2 \%$ chlorhexidine or octenidine) or the cuff pressure (30 or $100 \mathrm{cmH}_{2} \mathrm{O}$ ). Anatomical conditions, e.g., tongue size, mouth size, stoma size, and dentures, may affect the adequate evacuation of the oral rinse and promote the retention of the rinse.

Chlorhexidine and octenidine are cationic antiseptic rinses, which have comparable viscosity (comparable to water) and hepatics in handling. However, there are differences in their antiseptic properties. No allergic potential, antimicrobial resistance, or protein error are reported for octenidine; moreover, the biocompatibility index is better for octenidine. Chlorhexidine has allergenic potential and protein error, and a gram negative loophole has been reported; however, chlorhexidine offers the advantage of having widespread use, and longtime experiences with chlorhexidine have been reported [14].

The German institute of hygiene (Robert-Koch-Institut) has recommended octenidine as an antiseptic rinse for premature newborn infants under $1500 \mathrm{~g}$ bodyweight, and has classified it as harmless $[15,16]$. 
The leakage of about $30 \%$ of the rinse into the esophagus can be considered as non-hazardous due to the fact that chlorhexidine and octenidine are not resorbed by the gastro-intestinal tract owing to the cationic structure. The toxic side effects in the lungs are described for chlorhexidine [3,4]. However, comparable data have not been reported for octenidine. Adequate evacuation with a vacuum pump before deflation of the endotracheal cuff is the best comportment to prevent toxic effects of any solution in the lungs.

The study limitations must be considered when interpreting the results. First, in this study, only one endotracheal system (Magill tube system; no comparisons with the Woodbridge or Oxford-non-kinking tube system) was used, and no comparison with other systems was conducted. Second, the lower limit at which the leakage protection was lost was not determined. Third, a mechanical cleaning was not performed, which could have caused bias in the assessment of leakage protection; moreover, no continuous positive airway pressure or biphasic positive airway pressure ventilation was performed which may have also caused bias in the evaluation of the sealing between the trachea and endotracheal cuff.

In further studies, the microbial conditions and the potential for causing pneumonia of the cuff puddle should be investigated. The cuff puddle is likely a mixture of oral secretions, oral rinse, and skin flakes.

The sealing between an endotracheal tube cuff and the tracheal wall is leakage-proof during oral care with an antiseptic solution. However, approximately $30 \%$ of the applied antiseptic solution can leak into the esophagus, and approximately $10 \%$ can leak into the trachea after the cuff has been deflated.

\section{Acknowledgments}

This work was Funded by Schülke \& Mayr GmbH with a grant of $€ 1000$.

\section{References}

1. Ashraf M, Ostrosky-Zeichner L. Ventilator-associated pneumonia: a review. Hosp Pract (1995). 2012; 40: 93-105.

2. Coffin SE, Klompas M, Classen D, Arias KM, Podgorny K, Anderson DJ, et al. Strategies to prevent ventilator-associated pneumonia in acute care hospitals. Infect Control Hosp Epidemiol 2008; 29 Suppl 1: S31-40.

3. Xue Y, Zhang S, Yang Y, Lu M, Wang Y, Zhang T, et al. Acute pulmonary toxic effects of chlorhexidine (CHX) following an intratracheal instillation in rats. Hum Exp Toxicol 2011; 30: 1795-803.

4. Xue Y, Zhang S, Tang M, Zhang T, Wang Y, Hieda Y, et al. Comparative study on toxic effects induced by oral or intravascular administration of commonly used disinfectants and surfactants in rats. J Appl Toxicol 2012; 32: 480-7.

5. Emilson CG, Bowen WH, Robrish SA, Kemp CW. Effect of the antibacterial agents octenidine and chlorhexidine on the plaque flora in primates. Scand J Dent Res 1981; 89: 384-92.

6. Patters MR, Nalbandian J, Nichols FC, Niekrash CE, Kennedy JE, Kiel RA, et al. Effects of octenidine mouthrinse on plaque formation and gingivitis in humans. J Periodontal Res 1986; 21: 154-62.

7. Rokamp KZ, Secher NH, Moller AM, Nielsen HB. Tracheal tube and laryngeal mask cuff pressure during anaesthesia - mandatory monitoring is in need. BMC Anesthesiol 2010; 10: 20.

8. Hwang JY, Park SH, Han SH, Park SJ, Park SK, Kim JH. The effect of tracheal tube size on air leak around the cuffs. Korean J Anesthesiol 2011; 61: 24-9.

9. Oikkonen M, Aromaa U. Leakage of fluid around low-pressure tracheal tube cuffs. Anaesthesia 1997; 52: 567-9.

10. Nordin U. The trachea and cuff-induced tracheal injury. An experimental study on causative factors and prevention. Acta Otolaryngol Suppl 1977; 345: 1-71.

11. Seegobin RD, van Hasselt GL. Endotracheal cuff pressure and tracheal mucosal blood flow: endoscopic study of effects of four large volume cuffs. Br Med J (Clin Res Ed) 1984; 288: 965-8.

12. Hameed AA, Mohamed H, Al-Mansoori M. Acquired tracheoesophageal fistula due to high intracuff pressure. Ann Thorac Med 2008; 3: 23-5.

13. Make BJ, Hill NS, Goldberg AI, Bach JR, Criner GJ, Dunne PE, et al. Mechanical ventilation beyond the intensive care unit. Report of a consensus conference of the American College of Chest Physicians. Chest 1998; 113(5 Suppl): S289-344.

14. Muller G, Kramer A. Biocompatibility index of antiseptic agents by parallel assessment of antimicrobial activity and cellular cytotoxicity. J Antimicrob Chemother 2008; 61: 1281-7.

15. Recommendation for the prevention of nosocomial infections in neonatal intensive care patients with a birth weight less than 1,500 g. Report by the Committee of Hospital Hygiene and Infection Prevention of the Robert Koch Institute. Bundesgesundheitsblatt Gesundheitsforschung Gesundheitsschutz 2007; 50: 1265-303.

16. Buhrer C, Bahr S, Siebert J, Wettstein R, Geffers C, Obladen M. Use of 2\% 2-phenoxyethanol and $0.1 \%$ octenidine as antiseptic in premature newborn infants of 23-26 weeks gestation. J Hosp Infect 2002; 51: 305-7.

17. McHanwell S, Brenner E, Chirculescu AR, Drukker J, van Mameren H, Mazzotti G, et al. The legal and ethical framework governing Body Donation in Europe - A review of current practice and recommendations for good practice. Eur J Anat 2008; 12: 1-24. 